\title{
An exploration of parental barriers to appropriate portion sizes for young children: a qualitative study
}

\author{
L.K. Pourshahidi ${ }^{1}$, M.B.E. Livingstone ${ }^{1}$, L.E. McCotter ${ }^{1}$, T.A. McCaffrey ${ }^{2}$, H. McCarthy ${ }^{3}$ and \\ M.A. $\operatorname{Kerr}^{1}$ \\ ${ }^{1}$ Northern Ireland Centre for Food and Health (NICHE), Ulster University, Coleraine, BT52 1SA, UK \\ ${ }^{2}$ Department of Nutrition, Dietetics and Food, Monash University, Victoria, Australia and \\ ${ }^{3}$ College of Health and Biomedicine, Victoria University, Melbourne, Australia
}

Young children have an innate ability to self-regulate their energy intake $\mathrm{e}^{(1)}$ but evidence suggests that children as young as 1 -year may be susceptible to environmental triggers which can promote overeating ${ }^{(2-3)}$. The aim of this qualitative study was to assess current parental practices in the provision of appropriate food portion sizes (PS) for children aged 6-36 months.

Parents/carers of at least one child aged 6-36 months were recruited within local community groups/churches and crèches (male and female, $\geqslant 18$ years) and invited to attend one of eight focus groups ( $2 \mathrm{hrs} \mathrm{each;} n 3-9$ per group; total $n 46$ parent/carers). A discussion guide was developed for the focus groups to ensure that key themes were covered, but at the same time flexible enough to facilitate broader discussion as issues arose. Discussion topics included: healthy eating; the importance of PS; awareness of existing advice/guidance and its usefulness; opinions on new guidance needed (if any). Focus groups were transcribed verbatim and analysed using an inductive thematic procedure ${ }^{(\mathbf{4})}$ using NVivo 10 (QSR International).

In the majority, parent/carers were female (94\%), normal-weight (53\%), from urban locations $(80 \%)$, married (54\%) and were either employed part-time $(35 \%)$ or were full-time home-makers $(35 \%)$. The table outlines typical quotes from parents under each main theme. Parents did not recognise the importance of PS during the discussions on healthy eating or concerns about their child/children's diets. Parents commonly trust their own children to self-regulate their PS, although some were unsure the age at which children gained or lost this in-built control mechanism.

\begin{tabular}{|c|c|}
\hline Theme & Example quote \\
\hline Healthy eating and dietary concerns & $\begin{array}{l}\text { "It's making sure you're offering the right food, it's not necessarily about portion control at that age, it's just } \\
\text { about the variety and the quality of the food... they sort of do the portion control themselves." }\end{array}$ \\
\hline Current parental practices and awareness of portion size & $\begin{array}{l}\text { "I just can't imagine how a child overeats, I just can't imagine... except if they're getting the wrong food... } \\
\text { they're so clever at knowing when they're full and when they've had enough." } \\
\text { "... she is the type at the minute that she doesn't know when to stop... if I feel I've put too much in her bowl I will } \\
\text { stop..." } \\
\text { "I just judge by experience from the past" } \\
\text { "...it's passed down. So, you know, it's right through the family and very difficult to break that trend" } \\
\text { pleasant." }\end{array}$ \\
\hline Opinions of portion size guidance and tools & $\begin{array}{l}\text { "I think it's relatively inconsistent, it's all to do with the health visitor that you have" } \\
\text { "I wouldn't mind a guidance thing but I would definitely still be wanting the reassurance of, you know, just being } \\
\text { reminded that it is a guidance because every child is different." }\end{array}$ \\
\hline
\end{tabular}

Faced with a lack of guidance, many parents relied on and trusted their own judgements to determine an appropriate PS for their children, and this was typically based on habits ingrained from their own parents/family, or their own past experiences. When prompted, however, most would welcome additional advice from their healthcare professional on appropriate PS for children aged 6-36 months, albeit this may be difficult to implement owing to the wide number of factors that can influence a child's PS from meal-to-meal and day-to-day.

Future public health initiatives in this area are warranted. PS guidance should clearly highlight the role of early life eating patterns for the maintenance of a healthy weight and establishing future dietary habits, as well as being cognisant of the wide range of factors that can influence a child's food intake.

Ethical approval was obtained from the Biomedical Sciences Ethics Filter Committee, Ulster University (FCBMS-14-032). The study was funded by Nutricia Ltd and conducted according to the Declaration of Helsinki.

1. Birch LL \& Deysher M. (1986) Appetite 7, 323-331.

2. Fox MK, Devaney B, Reidy K et al. (2006) J Am Diet Assoc 106, S77-83.

3. Fisher JO, Liu Y, Birch LL et al. (2007) Am J Clin Nutr 86, 174-179.

4. Braun V \& Clarke V (2006) Qualitative research in psychology 3, 77-101. 